\title{
Serum erythropoietin concentrations in symptomatic infants during the anaemia of prematurity
}

Jill Meyer, Alan Sive, Peter Jacobs

\begin{abstract}
A comparison was carried out between a series of neonates who weighed less than $1500 \mathrm{~g}$ at birth and received red cell transfusions for symptomatic anaemia of prematurity (group $1, n=14$ ) and controls of similar gestational age and weight, who remained well and were not transfused during their nursery stay (group 2, $\mathbf{n = 1 0}$ ). Mean (SD) haemoglobin concentrations at birth were $163(12) \mathrm{g} / 1$ and 183 (17) $g / 1(p=0.004)$, respectively. Transfusion resulted in significantly better weight gain in six infants who had been growing poorly: mean (SE) $8.8(2.8) \mathrm{g} /$ day improved to $23.3(2.1) \mathrm{g} /$ day $(\mathbf{p}<0.002)$. Geometric mean (SD) serum immunoreactive erythropoietin (SiEp) concentrations $(17.7(1.3) \mathrm{U} / \mathrm{l})$ for the whole group of infants were similar to those of normal adults $(17.4(4 \cdot 7) \mathrm{U} / \mathrm{l})$ despite considerably reduced haemoglobin values. There was a significant inverse correlation between haemoglobin and log SiEp concentrations in the infants requiring transfusion $(r=-0.43$; $\mathbf{p}<0.01$ ), but this was not apparent in the untransfused babies. Moreover, at haemoglobin concentrations below $120 \mathrm{~g} / \mathrm{l}$ the mean (SE) SiEp concentration of $20(1.08) \mathrm{U} / 1$ in group 1 was significantly higher than in group $2(14(1.06) U / 1 ; p=0.002)$. These data suggest that an increased concentration of SiEp early in the course of the anaemia of prematurity helps to identify those infants who would benefit from red cell transfusions, but that clinical criteria, although ill defined, do so equally well.
\end{abstract}

Infants born prematurely experience an exaggerated fall in haemoglobin concentration compared with full term babies, ${ }^{1}$ a significant proportion of them manifesting clinical features of anaemia, ${ }^{2}$ where the common practice of transfusing red cells usually results in symptomatic improvement.

Recent studies have questioned the value and safety of such a practice in asymptomatic babies, particularly when based on packed cell volume figures alone. ${ }^{34}$ Furthermore, as the criteria for red cell infusions in these individuals are largely clinical and ill defined, attempts have been made to find a laboratory investigation which might prove a reliable guide to justify this potentially hazardous intervention. It is known that the serum erythropoietin concentrations in preterm infants are inappropriately low for the degree of anaemia ${ }^{5-8}$ when compared with adults with similar haemoglobin values, but that a physiological response to impaired tissue oxygenation will occur. Thus, increased concentrations of erythropoietin could identify infants who are hypoxic and who would be expected to benefit from additional red cells.

To test this postulate, serum immunoreactive erythropoietin (SiEp) concentrations in 14 infants transfused for symptomatic anaemia of prematurity were contrasted to 10 comparable babies who remained asymptomatic and untransfused throughout their nursery stay to establish whether the hormonal response differed in the two groups.

\section{Patients and methods}

Infants who were less than 34 weeks' gestation by Dubowitz score ${ }^{9}$ and whose birth weights were under $1500 \mathrm{~g}$ were studied. Those with congenital or inherited disease, haemolysis, cardiac pathology, or who suffered acute blood loss were excluded. Infants were managed by the attending neonatal staff, who made all decisions about their day to day care, although transfusion was restricted to babies with signs attributable to anaemia and not for a low haemoglobin concentration alone. Transfusions comprised packed red cells in citrate-phosphatedextrose-adenine 1 at a volume of $10 \mathrm{ml} / \mathrm{kg}$ of body mass. Folate, iron, and vitamin $\mathrm{E}$ were not given to any of the infants until the day before discharge.

Each infant was examined daily to document physical findings. Body weight, kilojoule intake, and all medical and supportive treatments were recorded until they were discharged at a weight of $2000 \mathrm{~g}$.

The first blood count was performed 12 hours after birth and then at weekly intervals, using a standardised capillary microtechnique on the Coulter S Plus 2, together with a corrected reticulocyte count on 2000 cells. In patients who were transfused, 48 hours elapsed before sampling. Serum ferritin, erythropoietin, fetal haemoglobin concentration $(\mathrm{HbF})$, and red cell 2,3-diphosphoglycerate (2,3-DPG) were measured. ${ }^{10-12}$ An aliquot of $1 \mathrm{ml}$ of venous blood was drawn every two weeks for SiEp, which was estimated using a radioimmunoassay $^{13}$; measurements were made in duplicate and in a single batch.

\section{STATISTICS}

Data were analysed using Student's $t$ test for difference between means, and correlation coefficients by the least mean squares best fit for linear regression. All analyses involving erythropoietin were performed after logarithmic 
transtormation, but stated as the antilogarithmic equivalents. Qualitative differences were assessed using the $\chi^{2}$ or Fisher's exact tests. Mean and standard error of the mean are given to facilitate comparison between groups.

\section{Results}

Of 24 infants studied, 14 received packed red cells (group 1) and 10 were not transfused (group 2). Indications for this intervention were failure to gain weight, lethargy, apnoea, or clinical findings suggestive of a patent ductus arteriosus when accompanied by a capillary packed cell volume reduced below $0 \cdot 35$. The clinical signs resolved after this procedure in all but one patient, in whom a patent ductus arteriosus murmur persisted. Six infants were transfused on two occasions.

Packed red cell transfusion resulted in an improved rate of weight gain (mean (SE) $23 \cdot 3$ $(2 \cdot 1) \mathrm{g} /$ day in the week after transfusion) in six infants who were growing poorly the week before (mean (SE) $8.8(2 \cdot 8) \mathrm{g} /$ day; $\mathrm{p}<0.002$ ).

Summary of clinical and haematological data of study infants. Data are expressed as mean $(S E M)$

\begin{tabular}{|c|c|c|c|c|}
\hline & Group 1 (n & 14) & $u p 2(n=10)$ & Significance \\
\hline \multirow[t]{2}{*}{$\begin{array}{l}\text { Birth weight (g) } \\
\text { Gestational age (weeks) } \\
\text { Days to regain birth weight } \\
\text { Days requiring intensive care } \\
\text { No requiring ventilatory support } \\
\text { Haemoglobin at birth (g/l) }\end{array}$} & $\begin{array}{l}1176(34) \\
31 \cdot 5(0 \cdot 3) \\
11(1 \cdot 4) \\
8 \cdot 1(1 \cdot 2) \\
4 \\
163(3)\end{array}$ & & $\begin{array}{l}1267(33) \\
31 \cdot 6(0 \cdot 3) \\
7(1 \cdot 2) \\
6 \cdot 2(1 \cdot 3) \\
5 \\
183(5)\end{array}$ & $\begin{array}{l}\text { NS } \\
\text { NS } \\
\mathrm{p}=0.04 \\
\mathrm{p}=0.0001\end{array}$ \\
\hline & \multicolumn{2}{|l|}{ Transfusion } & $\begin{array}{l}\text { Throughout } \\
\text { study }\end{array}$ & \\
\hline $\begin{array}{l}\text { HbF }(\%) \\
\text { Red cell } 2,3 / \mathrm{DPG}(\mathrm{nmol} / \mathrm{ml}) \\
\text { FDPGF }(\mathrm{nmol} / \mathrm{ml})\end{array}$ & $\begin{array}{l}\text { Before } \\
81 \cdot 7(1 \cdot 9) \\
4764(289) \\
809(187)\end{array}$ & $\begin{array}{l}\text { After } \\
45 \cdot 1(5 \cdot 7) \\
5460(187) \\
2734(296)\end{array}$ & $\begin{array}{l}81 \cdot 7(1 \cdot 9) \\
5515(328) \\
1070(90)\end{array}$ & $\begin{array}{l}\mathbf{p}=0.0001^{* *} \\
\mathbf{p}=0.05^{* *} \\
\mathbf{p}=0.0001^{* *}\end{array}$ \\
\hline $\begin{array}{l}\text { Serum ferritin on discharge }(\mu \mathrm{g} / \mathrm{l}) \\
\text { Haemoglobin at discharge }(\mathrm{g} / \mathrm{l}) \\
\text { Days spent in hospital }\end{array}$ & $\begin{array}{l}336(32) \\
121(5) \\
51(3)\end{array}$ & & $\begin{array}{l}374(42) \\
101(2 \cdot 8) \\
39(2)\end{array}$ & $\begin{array}{l}p=0.003^{* *} \\
p=0.004^{* *}\end{array}$ \\
\hline
\end{tabular}

FDPGF $=$ functioning diphosphoglycerate fraction

${ }^{*}$ Intensive care assessed as need for oxygen and/or intravenous fluids.

**Significance of difference between values before and after transfusion.

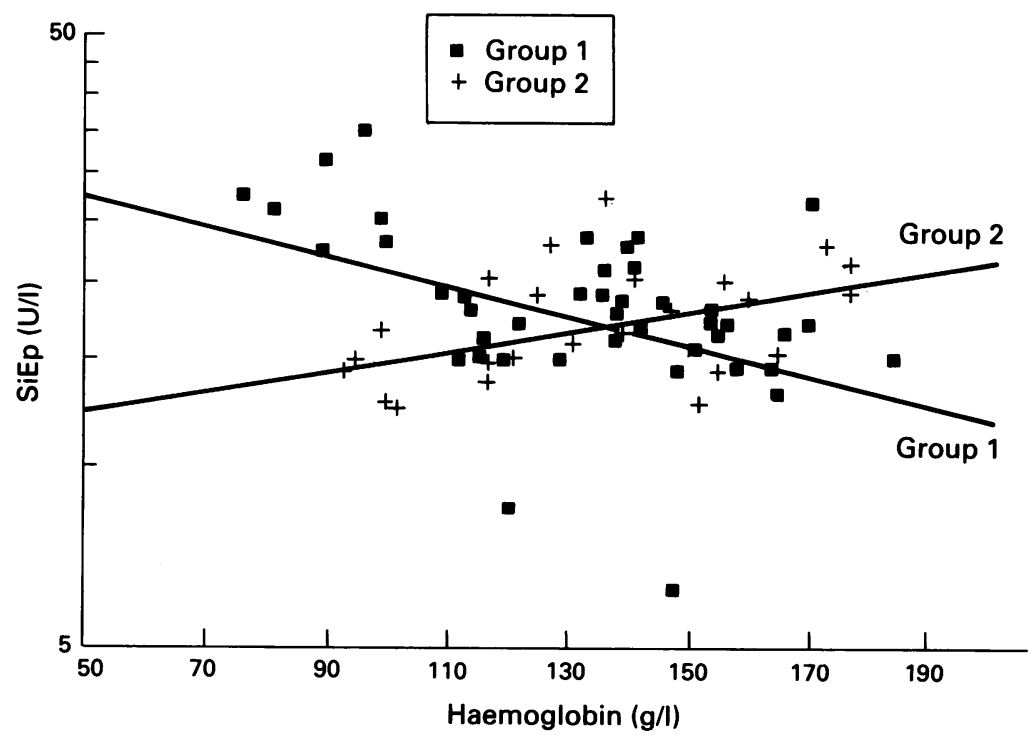

Relationship between SiEp and haemoglobin concentrations for transfused (group 1) and untransfused (group 2) infants. The correlation coefficients obtained by least squares linear regression were $r=-0.43,(p<0.01)$ and $r=0.45(p<0.05)$ respectively.
The mean (SE) rates of weight gain in the eight remaining infants in group 1 during the equivalent periods were $26 \cdot 1(2 \cdot 6)$ and $24 \cdot 0$ $(1 \cdot 8) \mathrm{g} /$ day respectively, which were not significantly different from those in group 2 , calculated over a similar period $(20.9(3 \cdot 1)$ and $24.9(2 \cdot 4)$ g/day).

The table summarises the clinical and haematological data of the infants during the study period. The two groups were comparable at delivery in terms of gestational age, birth weight, and Apgar scores. However, the mean (SD) haemoglobin concentration at birth was significantly lower in group 1 (163 (12 g/l) than in those infants who did not sübsequently require a transfusion (183 (17) $\mathrm{g} / \mathrm{l} ; \mathrm{p}=0.004)$. There was a significant correlation between the haemoglobin at birth and the time to the first red cell transfusion $(r=0.72 ; p<0.02)$. The infants who required red cell transfusions took significantly longer to regain their birth weights $(p=0.04)$. They also required intravenous fluids, ventilatory support, and supplemental oxygen for approximately two days longer than the untransfused infants, but this difference did not achieve statistical significance. Group 1, however, required a significantly longer (average 12 days) period of hospitalisation $(p=0.004)$.

Although the mean haemoglobin concentration in group 1 was lower than that in group 2 at all times before transfusion, the rate of fall was similar in the two groups. In both groups there was a gradual upward drift in the reticulocyte count from two weeks after birth. This phenomenon seemed to disappear after transfusion, but persisted in the untransfused infants. Differences in the reticulocyte counts between the two groups did not reach statistical significance at any time.

The concentration of circulating red cell 2,3DPG, $\mathrm{HbF}$, and the calculated functioning DPG fraction (FDPGF) (the product of percentage haemoglobin $\mathrm{A}(\mathrm{HbA})$ and total red cell 2,3-DPG) were similar to those reported for a comparable group of infants. ${ }^{14}$ Red cell transfusion resulted in the expected changes in these measurements because of the $\mathrm{HbA}$ content of the transfused cells (table). The measurements did not change significantly in the untransfused infants.

The range for SiEp concentration was 6.2$35 \cdot 2 \mathrm{U} / \mathrm{l}$. The geometric mean (SD) SiEp concentration for all the samples was 17.7 (1.3) $\mathrm{U} / \mathrm{l}$, which is similar to that of $17 \cdot 4(4 \cdot 72) \mathrm{U} / \mathrm{l}$ for normal adults using the same assay. Significant differences between the two groups were observed when the mean SiEp concentrations were related to the haemoglobin concentrations. Thus, in the symptomatic infants (group 1) who had haemoglobin values below $120 \mathrm{~g} / \mathrm{l}$, the mean (SE) SiEp concentration was $20(1.08) \mathrm{U} / 1$, significantly higher than the concentration of 14 $(1.06) \mathrm{U} / \mathrm{l}$ in the asymptomatic infants in group $2(p=0.002)$. The haemoglobin concentrations in both these groups were low (104 (3.8) and $104(3.6) \mathrm{g} / \mathrm{l}$ respectively) and not significantly different. The age at the time of sampling was also similar at $37.7(3.5)$ and $36.9(3.4)$ days respectively.

Appreciable differences between the two 
groups were also demonstrated when log $\mathrm{SiEp}$ concentrations were correlated with haemoglobin concentrations (figure). In group 1 there was a significant negative correlation between the haemoglobin concentration and the log $\mathrm{SiEp}$ concentration $(r=-0.43 ; p<0.01)$ for all samples analysed. This relationship did not pertain in group 2, where the correlation between the haemoglobin and SiEp was positive $(r=0.45$; $\mathrm{p}<0.05$ ). At haemoglobin concentrations less than $120 \mathrm{~g} / 1$ the negative correlation between $\log \mathrm{SiEp}$ and haemoglobin concentrations in group 1 became stronger $(r=-0.816 ; p<0.001)$, while the positive correlation in the group 2 infants became weaker $(r=0.317)$ and lost statistical significance. Interdependence of data points was excluded by examining the paired data for each infant at the age of 3-4 weeks, where similar correlations were obtained.

\section{Discussion}

The rapid fall in the haemoglobin concentration in preterm infants shortly after birth is referred to as the physiological anaemia of prematurity. In some instances this is not accompanied by any adverse response, when this designation may be reasonable. In contrast, a number of infants do benefit from red cell transfusions, and the anaemia in these may not be so benign. Attempts have been made to predict when benefit will accrue from such intervention, but these have so far met with limited success.

In this study we studied differences in the SiEp concentration in preterm infants who were clinically adjudged to require transfusion and those who were not, and investigated the hypothesis that these differences might provide a quantitative measure of the group at risk. Indeed, the results indicate that symptomatic infants with low haemoglobin concentrations have higher SiEp concentrations than those who are asymptomatic with corresponding degrees of anaemia. Presumably, the higher SiEp concentrations in the symptomatic infants reflect low central venous oxygen tension and tissue hypoxia $^{8}$ and would support the decision to transfuse using standard clinical criteria. This approach is strengthened by the fact that after the transfusions there was improvement in weight gain and resolution of the signs for which the red cells were infused.

Not all investigators have found red blood cells to be of benefit to the infant. Keyes et al reported that such a step, even when the packed cell volume was low, did not predictably alter the heart rate or respiratory rate nor decrease the frequency of bradycardia or apnoea. ${ }^{15}$ Changes in the weight gain before and after transfusion are not stated. The SiEp concentrations in their symptomatic patients were not increased, possibly because the levels were suppressed by previous transfusions. In our patients $\mathrm{SiEp}$ concentrations were increased only in those patients who were symptomatic before they were transfused. It is possible that the threshold for the clinical decision to transfuse is higher in our nursery. Alternatively, as most of our infants only received one transfusion this may have been insufficient to cause sup- pression of the SiEp concentrations, as might have occurred with multiple transfusions in the infants studied by Keyes et al.

The increase in weight in certain of our infants after transfusion differs from the findings of others who failed to show this effect. ${ }^{34}$ These investigators studied infants who received 'top-up' transfusions to maintain the haemoglobin concentration above $100 \mathrm{~g} / \mathrm{l}$. In contrast, the infants in our study who increased their rate of weight gain were growing poorly before this intervention. These findings suggest that selected infants may benefit from transfusion and accord with the findings of Stockman and Clark. ${ }^{16}$ They reported that infants with haemoglobin concentrations below $75 \mathrm{~g} / 1$ significantly increased their rate of weight gain in the week after transfusion. Although six of the 14 transfused infants showed enhanced weight gain, we were unable to demonstrate a significant difference in SiEp concentrations in these six babies compared with the eight in whom weight gain remained constant. The small number of infants in the subgroups precluded adequate analysis of the interrelationship between haemoglobin, $\mathrm{SiEp}$, and weight gain. A larger study would be needed to answer this question.

A number of previous studies have examined the relationship between the haemoglobin and SiEp concentrations in preterm infants. Stockman et al showed a weak inverse correlation between these parameters. ${ }^{8}$ The magnitude of the SiEp response appears to be more dependent on the position of the haemoglobinoxygen dissociation curve and tissue oxygenation than on the absolute haemoglobin concentration. In this study we could not demonstrate a negative correlation between haemoglobin concentration and SiEp for the patients as a whole. However, once the patients were divided according to whether they were symptomatic or not, a clear inverse relationship became apparent in the former group. This suggests that only the symptomatic patients with significantly increased SiEp concentration had tissue hypoxia or higher percentages of $\mathrm{HbF}$ as their haemoglobin concentrations were not lower than the untransfused patients. The amounts of $\mathrm{HbF}$ in our patients were all similar. Previous studies have not divided patients on the basis of their symptomatology or, alternatively, have only followed up infants who were either all transfused or not transfused.

Our study suggests that some infants do benefit from red cell transfusion and that the anaemia in these babies is pathological. The reticulocyte count and haemoglobin concentrations are unhelpful in deciding which infants to transfuse. An increase SiEp concentration early in the course of the anaemia appears to be ineffectual in eliciting a reticulocyte response, but it may predict which infants would be likely candidates for treatment with recombinant erythropoietin as an alternative to transfusion. The overlap of individual $\mathrm{SiEp}$ values between the two groups of patients suggests that serial concentrations would be more informative than an isolated estimate. The SiEp concentrations remained constant in the asymptomatic infants throughout the study period. 
Rising values in the first four weeks of life may indicate tissue hypoxia and the need for intervention by red cell infusion or, alternatively, the administration of recombinant erythropoietin. In contrast, patients with increased SiEp concentrations later on, as reported by Brown $e t a l,{ }^{5}$ do exhibit a reticulocyte response. Intervention by transfusion in these infants would therefore seem unnecessary.

Sensitive, reliable erythropoietin assays are not readily available to the majority of centres caring for newborn infants. This study has shown that in the absence of an erythropoietin measurement it is not the haemoglobin concentration but clinical criteria, which accord with increased SiEp concentrations, that should be used to justify additional red cells for the preterm infant. The use of clinical criteria for transfusion also has limitations as it is dependent on the observer and practice varies between units.

This study was supported by the University of Cape Town Leukaemia Centre and Staff Research (Cancer and Foote) Fund, the Gwendoline Moore Trust, the Medical Research Council, the National Cancer Association, and the Michael Chanani, Kaliski and $M$ A Richardson Bequests.

We thank Keith Hart for the art work, Dr Gisela Clemons for erythropoietin assay, and Jackie Davies for help with preparation of the manuscript and its typing.

1 Dallman PR. Anemia of prematurity. Ann Rev Med 1981;32:

2 Wardrop CAJ, Holland BM, Veale KEA, Jones JG, Gray OP. Wardrop CAJ, Holland BM, Veale KEA, Jones JG, Gray OP.
Non-physiological anemia of prematurity. Arch Dis Child 1978;53:855-60. 3 Blank JP, Sheagren TG, Vajaria J, Mangurten HH, Benawra
RS, Puppala BL. The role of RBC transfusion in the premature infant. Am 7 Dis Child 1984;138:831-3.

4 Ransome OJ, Moosa EA, Mothebe FM, Spector I. Are regular 'top-up' transfusions necessary in otherwise well,
growing premature infants? $S$ Afr Med $\mathcal{f} 1989 ; 75: 165-6$.

5 Brown MS, Phibbs RH, Garcia JF, Dallman PR. Postnatal changes in erythropoietin levels in untransfused premature changes in erythropoietin levels in

6 Brown MS, Garcia JF, Phibbs RH, Dallman PR. Decreased response of plasma immunoreactive erythropoietin to 'available oxygen' in anemia of prematurity. $\mathcal{F}$ Pediatr 1984;105:793-8.

7 Stockman JA, Garcia JF, Oski FA. The anemia of prematurity. Factors governing the erythropoietin response. $N$ Engl f Med 1977;296:647-50.

8 Stockman JA, Graeber MD, Clark DA, McLellan K, Garcia JF, Kavey REW. Anemia of prematurity: determinants of the erythropoietin response. $\mathcal{f}$ Pediatr 1984;105:786-92.

9 Dubowitz LMS, Dubowitz V, Goldberg C. Clinical assessment of gestational age in the newborn infant. $\mathcal{F}$ Pediatr 1970;77:1-10.

10 Dempster WC, Steyn DL, Knight GL, DeV Heese H. Immunoradiometric assay of serum ferritin as a practical method for the evaluation of iron stores in infants and children. Med Lab Sci 1977;34:337-44.

11 Pembrey ME, McWade P, Weatherall DJ. Reliable routine estimation of small amounts of foetal haemoglobin by alkali estimation of small amounts of foetal haemoglobit
denaturation. $\mathcal{f}$ Clin Pathol 1972;25:738-40.

12 Lowry OH, Passonneau JV, Hasselberger FX, Schulz DW. Effect of ischemia on known substrates and cofactors of the glycolytic pathway in the brain. $\mathcal{F}$ Biol Chem 1964;239: 18-30.

13 Garcia JF, Ebbe SN, Hollander L, Cutting HO, Miller ME, Cronkite EP. Radioimmunoassay of erythropoietin: circulating levels in normal and polycythemic human beings. f Lab Clin Med 1982;99:624-35.

14 Delivoria-Papadopoulos M, Roncevic NP, Oski FA. Postnatal changes in oxygen transport of term, premature and sick infants: the role of 2,3-diphosphoglycerate and adult haemoglobin. Pediatr Res 1971;5:235-45.

15 Keyes WG, Donohue KP, Spivak JL, Jones DM, Oski FA. Assessing the need for transfusion of premature infants and role of haematocrit, clinical signs, and erythropoietin level. Pediatrics 1989;84:412-7.

16 Stockman J, Clark DA. Weight gain: a response to transfusion in selected preterm infants. Am $\mathcal{f}$ Dis Child fusion in selected 